\title{
Exhaled nitric oxide correlates with IL-2, MCP-1, PDGF-BB and TIMP-2 in exhaled breath condensate of children with refractory asthma
}

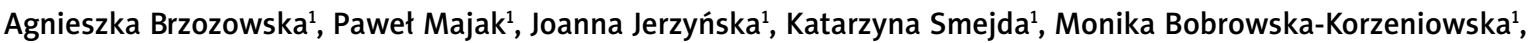 \\ Włodzimierz Stelmach², Magdalena Koczkowska ${ }^{3}$, Iwona Stelmach ${ }^{1}$
}

\author{
${ }^{1}$ Department of Pediatrics and Allergy, Medical University of Lodz, Lodz, Poland \\ Head of the Department: Prof. Iwona Stelmach MD, PhD \\ ${ }^{2}$ Department of Social and Preventive Medicine, Medical University of Lodz, Lodz, Poland \\ Head of the Department: Włodzimierz Stelmach MD, PhD \\ ${ }^{3}$ Department of Biology and Genetics, Medical University of Gdansk, Gdansk, Poland \\ Head of the Department: Prof. Janusz Limon MD, PhD
}

Postep Derm Alergol 2015; XXXII, 2: 107-113

DOI: $10.5114 /$ pdia.2014.40953

\begin{abstract}
Introduction: There is evidence that parameters obtained from exhaled breath condensate (EBC) reflect changes in the level of the airway lining fluid. The telation between exhaled nitric oxide (NO) and EBC inflammatory markers has not been analyzed in the context of the inflammatory profile in the airways in asthmatic children.

Aim: To show the cytokine profile in EBC of children with severe/refractory asthma as well as correlations between the fractional exhaled NO (FeNO) level and cytokine concentrations.

Material and methods: The study population consisted of eight children aged 8 to 17 years with IgE-dependent, severe/refractory asthma with a duration of at least 2 years. This was an observational study, the first consecutive eight patients with asthma symptoms on the day of the study visit, when EBC samples were obtained.

Results: The inter-subject variability of study cytokines ranged from 8.6 to 54.6. Cytokines with coefficient of variation < 20\% were: interferon- $\gamma$, interleukins IL-2, IL-7, IL-15, IL-16, monokine induced by interferon $\gamma(\mathrm{MIG})$ and tumor necrosis factor $\alpha$. We showed a significant positive correlation between the FeNO level and crucial mediators in asthma development and progression (IL-2, MCP-1), and potent markers of airway remodeling (PDGFBB, TIMP-2). All correlations between two different variables were controlled for the effects of age, forced expiratory volume in $1 \mathrm{~s}$ and number of asthma exacerbations during last 12 months.

Conclusions: The profiling of cytokine expression in EBC can be reproducibly performed in children with severe/ refractory asthma. When treating asthma in children, the FeNO level should be monitored as a prevention strategy of the progression of the remodeling leading to refractory/severe asthma. Exhaled breath condensate may be a useful tool to phenotype asthma via a non-invasive approach.
\end{abstract}

Key words: nitric oxide, cytokines, exhaled breath condensate, children, refractory asthma.

\section{Introduction}

Despite some methodological problems of the collection of exhaled breath condensate (EBC), its non-invasive nature gives an opportunity for repeated measurements for the same person and provides valuable information for the assessment of airway inflammation. There is evidence that parameters obtained from EBC reflect changes in the level of airway lining fluid and theoretically allows assessment of the severity of asthma and may provide some guidance for adjustment of drug therapy $[1,2]$. Exhaled breath condensate may also correlate with lung function impairment, airway remodeling and different aspects of the disease such as exercise induced bronchoconstriction (EIB). Despite rapidly increasing data

Address for correspondence: Prof. Iwona Stelmach MD, PhD, Department of Pediatrics and Allergy, Nicolaus Copernicus Hospital, 62 Pabianicka St, 93-513 Lodz, Poland, phone: +48 4268959 72, fax: +48 4268959 73, e-mail: alergol@kopernik.lodz.pl Received: 28.10.2013, accepted: 23.11.2013. 
on inflammatory markers in EBC, until now only few research groups reported on the concentration of the cytokines in EBC of children with severe asthma.

Severe asthma is an uncommon, poorly understood and heterogeneous disease [3]. A subgroup of these patients have more troublesome disease requiring high medication to maintain control of the disease or persistent symptoms, asthma exacerbations, or airflow obstruction despite high medication use, which is defined as "refractory asthma" [4].

The role of exhaled nitric oxide (NO) in clinical asthma management has been recently disputed [5]. However, a relation between exhaled $\mathrm{NO}$ and clinical parameters has not been analyzed in the context of the inflammatory profile in the airways in asthmatic children.

\section{Aim}

Therefore, we aimed to show the cytokine profile in EBC of children with severe/refractory asthma as well as correlations between the fractional exhaled NO (FeNO) level and cytokine concentrations.

\section{Material and methods}

\section{Patients}

The study population consisted of 8 children aged 8 to 17 years with asthma diagnosed on the basis of the symptoms and an improvement in the prebronchodilator forced expiratory volume in $1 \mathrm{~s}\left(\mathrm{FEV}_{1}\right)$ of $\geq 12 \%$ after administration of salbutamol $(400 \mu \mathrm{g})$ [6]. The first consecutive eight patients with severe/refractory asthma, symptomatic on the day of the study visit who fulfilled inclusion criteria were recruited. Patients were on a longterm therapy with high-dose inhaled corticosteroids ( $\geq 800 \mu$ g of budesonide) in combination with a long-acting $\beta_{2}$-agonist and a leukotriene receptor antagonist. None of the patients was a smoker.

\section{Inclusion criteria}

Severe/refractory asthma with a duration of at least 2 years, with persistent symptoms/exacerbation requiring hospitalization despite high-dose inhaled corticosteroid/long-acting beta agonist (ICS/LABA) and at least step-4 treatment [6].

\section{Exclusion criteria}

Inability to perform the EBC procedure properly, active smoking, other chronic respiratory tract disease.

\section{Ethics}

This study was approved by the Medical Ethics Committee of the Medical University. All parents or guardians and children provided written consent to participation in the study.

\section{Nitric oxide measurement}

Fractional exhaled NO measurements were performed prior to spirometry and exercise testing, according to the European Respiratory Society/American Thoracic Society (ERS/ATS) recommendations [7] with a chemiluminescence analyzer (model 280i nitric oxide analyzer; Sievers, Boulder, CO, USA) and defined in parts per billion. The analyzer provides an on-line continuous measurement of NO in a single exhalation with a detection range of 0.1 to 500 ppb. Environmental NO was measured before and after each test and never exceeded $5 \mathrm{ppb}$. All subjects were studied in the sitting position, without wearing a nose clip. The subjects exhaled at a constant flow rate $(50 \mathrm{ml} / \mathrm{s})$ from total lung capacity to residual volume without breath holding. They maintained a constant mouth pressure $\left(17 \mathrm{~cm} \mathrm{H}_{2} \mathrm{O}\right)$ by monitoring a visual display in order to eliminate contamination from nasal NO. Dead space and nasal NO (which are reflected by the NO concentration peak during exhalation) and NO from the lower respiratory tract (determined by the plateau value after the peak) were recorded automatically by using the manufacturer's software. Three FeNO measurements of the plateau phase were obtained, with less than $10 \%$ variation. The mean value of 3 successive reproducible recordings was retained for statistical analysis.

\section{Exhaled breath condensate collection}

Exhaled breath condensate samples were collected through EcoScreen-II device (Viasys Healthcare $\mathrm{GmbH}$, Berlin, Germany). Samples of EBC were obtained from children during tidal breathing while wearing a nose clip, as described previously [8]. The two-way non-rebreathing valves and tubing to the condenser served as a saliva trap. After collection (during $10 \mathrm{~min}$ ), EBC was rapidly frozen in small plastic tubes at $-80^{\circ} \mathrm{C}$ using dry ice and was stored at $-80^{\circ} \mathrm{C}$ until analysis.

\section{Analysis of exhaled breath condensate}

The material was the exhaled breath condensate of 8 children diagnosed with asthma. The analysis was performed using Quantibody Human Inflammation Array 3 (RayBiotech, Norcross, GA, USA) according to the manufacturer's instructions. This multiplex ELISA array kit allows quantitative measurement of 40 human cytokines. Each standard glass slide consists of 16 wells, each with an identical cytokine antibody array. All antibodies and positive controls are printed in quadruplicate in every well.

In the first step, the capture antibody was bound to the glass surface of the slide. Next, $100 \mu$ l of each patient sample and the array specific cytokine standards of known concentration were added to each well. After incubation for $2 \mathrm{~h}$ at room temperature, the array was washed 5 times with $150 \mu$ l of Wash Buffer I and twice 
with $150 \mu$ l of Wash Buffer II, 5 min per wash. Next, the array was incubated for $2 \mathrm{~h}$ with $1.4 \mathrm{ml}$ of the biotin - conjugated antibody at room temperature. Then, the washing protocol was repeated before the addition of $80 \mu \mathrm{l}$ of Cy3 equivalent dye-conjugated streptavidin to each well for $1 \mathrm{~h}$. After washing the array, the fluorescence signal was detected and quantified with the Axon GenePix 4000B scanner and GenePix Pro 6.0 software (Molecular Devices). The results were analyzed using Q-Analyzer Software (RayBiotech, Norcross, GA, USA).

\section{Statistical analysis}

For each cytokine concentration, inter-subject variability was assessed using a coefficient of variation (CV). The coefficient of variation was estimated according to the following rule: SD/mean $\times 100 \%$. The associations between study variables were assessed by partial correlation analysis. The partial correlations procedure computes correlation coefficients that describe the linear relationship between two variables while controlling for the effects of other additional variables. Partial correlations analysis was done for all study cytokines irrespective of their CV. To determine differences between the groups, Mann-Whitney test was used. All statistical analyses were performed using StatSoft Statistica for Windows, release 8.0 (StatSoft, Inc., Tulsa, USA). Values of $p<0.05$ was used as a definition of statistical significance.

\section{Results}

Eight children were recruited for this study. Detailed characteristics are shown in Table 1.

\section{Detections of cytokines}

Lower detection limits for all cytokines are given in Table 2. When the concentrations were below the detection limit in more than $50 \%$ of observations, cytokines were excluded from the analysis $(n=20)$.

\section{Inter-subject variability}

The inter-subject variability of study cytokines ranged from 8.6 to 54.6 (Table 2). Cytokines with CV< 20\% were: IFN- $\gamma$, interleukins IL-2, IL-7, IL-15, IL-16, monokine induced by interferon $\gamma(\mathrm{MIG})$ and tumor necrosis factor $\alpha$ (TNF- $\alpha$ ).

\section{Correlations}

We conducted the correlation analysis between the FeNO level and cytokines concentration in EBC. All correlations between two different variables were controlled for the effects of age, FEV and number of asthma exacerbation during last 12 months. The results of all correlation analyses are shown in Table 2. We showed a significant positive correlation between the FeNO level and IL-2, monocyte chemoattractant protein-1 (MCP-1), platelet-derived growth factor BB (PDGFBB) and tissue inhibitory of metalloproteinase 2 (TIMP2) (Figure 1). We conducted a partial correlation between cytokines included into the analysis. Significant and independent correlations have been found (Table 3). Additionally, we observed a significant correlation between FEV and IL-10 ( $R=0,855 ; p<0.001)$; all other cytokines were not correlated with $\mathrm{FEV}_{1}$ in our patients.

\section{Discussion}

Our manuscript addresses an important issue on correlations of airway inflammatory markers in exhaled

Table 1. Characteristics of study patients

\begin{tabular}{|c|c|c|c|c|c|c|c|c|}
\hline \multirow[t]{2}{*}{ Parameter } & \multicolumn{8}{|c|}{ Patients } \\
\hline & 1 & 2 & 3 & 4 & 5 & 6 & 7 & 8 \\
\hline Age [years] & 17 & 8 & 8 & 17 & 17 & 16 & 17 & 17 \\
\hline Gender & Male & Male & Female & Female & Male & Female & Female & Male \\
\hline $\begin{array}{l}\text { Asthma duration } \\
\text { [years] }\end{array}$ & 6 & 3 & 2 & 8 & 7 & 10 & 5 & 2 \\
\hline $\mathrm{FEV}_{1}[\%$ pred.] & 84.8 & 88 & 82.4 & 73.6 & 95.2 & 76 & 72 & 100.8 \\
\hline FeNO [ppb] & 8.9 & 30.8 & 31.6 & 108 & 15.6 & 251 & 71.2 & 23.7 \\
\hline Allergy profile & $\begin{array}{l}\text { Seasonal/ } \\
\text { perennial }\end{array}$ & Seasonal & Seasonal & $\begin{array}{l}\text { Seasonal/ } \\
\text { perennial }\end{array}$ & Seasonal & $\begin{array}{l}\text { Seasonal/ } \\
\text { perennial }\end{array}$ & $\begin{array}{l}\text { Seasonal/ } \\
\text { perennial }\end{array}$ & $\begin{array}{l}\text { Seasonal/ } \\
\text { perennial }\end{array}$ \\
\hline Cat allergy & Yes & No & No & Yes & No & No & Yes & Yes \\
\hline $\begin{array}{l}\text { Current allergy } \\
\text { exposure }\end{array}$ & Yes & No & No & Yes & No & Yes & Yes & Yes \\
\hline $\begin{array}{l}\text { Asthma } \\
\text { exacerbation * }\end{array}$ & 2 & 2 & 2 & 1 & 1 & 5 & 3 & 3 \\
\hline
\end{tabular}

*Number of asthma exacerbations requiring hospitalization during last 12 months. 
Table 2. Descriptive statistics and partial correlations between study variables

\begin{tabular}{|c|c|c|c|c|c|c|}
\hline Variables & $\begin{array}{c}\text { Mean } \\
{[\mathrm{pg} / \mathrm{ml}]}\end{array}$ & $\mathrm{SD}[\mathrm{pg} / \mathrm{ml}]$ & $\begin{array}{c}\text { Range } \\
{[\mathrm{pg} / \mathrm{ml}]}\end{array}$ & $\begin{array}{l}\text { Lower detection limit } \\
{[\mathrm{pg} / \mathrm{ml}]}\end{array}$ & $\begin{array}{l}\text { Coefficient of variation } \\
(\mathrm{SD} / \text { mean } \times 100 \%)\end{array}$ & $\begin{array}{l}\text { Correlations with } \\
\text { FeNO [ppb]^ }\end{array}$ \\
\hline IFN- $\gamma$ & 10.9 & 1.6 & 4.6 & 8.9 & 14.9 & 0.508 \\
\hline IL-1a & 19.5 & 10.6 & 32 & 14.5 & 54.6 & 0.176 \\
\hline IL-1ra & 125.6 & 39.4 & 128.1 & 67.4 & 31.3 & 0.155 \\
\hline IL-2 & 41 & 7.4 & 22.9 & 19.9 & 18 & $0.777^{\star}$ \\
\hline IL-5 & 28.9 & 8.9 & 26.7 & 22.0 & 30.6 & 0.032 \\
\hline IL-6 & 16.4 & 4 & 12.1 & 9.6 & 24.3 & 0.631 \\
\hline IL-7 & 24.3 & 2.9 & 8.4 & 16.9 & 12.1 & 0.054 \\
\hline IL-8 & 3.9 & 0.8 & 2.3 & 2.9 & 21.3 & 0.583 \\
\hline IL-12p70 & 4.6 & 0.9 & 2.9 & 3.0 & 20.1 & 0.231 \\
\hline IL-13 & 11.8 & 3.1 & 8.6 & 7.5 & 26.5 & -0.478 \\
\hline IL-15 & 65.4 & 12.3 & 35.6 & 24.1 & 18.9 & 0.485 \\
\hline IL-16 & 33.7 & 4.3 & 14 & 24.4 & 12.7 & -0.084 \\
\hline IL-17 & 135 & 53.9 & 165.8 & 115.0 & 39.9 & 0.118 \\
\hline MCP-1 & 81.5 & 23.6 & 69.9 & 29.1 & 28.9 & $0.752^{*}$ \\
\hline MIG & 188.1 & 36.1 & 91.4 & 84.0 & 19.2 & 0.06 \\
\hline MIP-1a & 40.8 & 18.3 & 48.8 & 16.5 & 44.8 & 0.582 \\
\hline MIP-1b & 2.9 & 0.8 & 2.1 & 1.6 & 25.7 & 0.475 \\
\hline PDGFBB & 6.8 & 3.3 & 9.5 & 6.3 & 47.8 & $0.942^{\star *}$ \\
\hline TIMP-2 & 302.1 & 150.7 & 410.7 & 212.9 & 49.9 & $0.734^{*}$ \\
\hline TNF- $\alpha$ & 34.4 & 3 & 9.5 & 13.5 & 8.6 & 0.176 \\
\hline
\end{tabular}

AAll correlations between two different variables were controlled for the effects of age, FEV and number of asthma exacerbations. Data presented as a correlation coefficient. ${ }^{*}$ Correlation is significant at the 0.05 level (2-tailed). ${ }^{* *}$ Correlation is significant at the 0.01 level (2-tailed).

breath with FeNO. Although the enthusiasm for the paper is tempered by the small number of study subjects, our results confirmed that various cytokines reflecting different aspects of inflammation could be found in the airways of severe/refractory asthmatic children. Here we showed correlations between the FeNO level and IL-2 and MCP-1, crucial mediators in asthma development and progression. Suppression of the lung expression of IL-2 protects against allergen-related Th2-type airway inflammation and hyperresponsiveness [9] and IL-2 inhalation therapy in patients with metastasizing renal cell carcinoma is capable of temporarily inducing symptomatic, functional and inflammatory alterations similar to those of bronchial asthma [10]. It has been shown that MCP-1 in EBC of asthmatic children was significantly increased in comparison with healthy controls [11]. What is more, MCP-1 is significantly higher in patients with refractory asthma compared to those with chronic well-controlled asthma $[12,13]$. Monocyte chemoattractant protein-1 has been found as one of the markers defining the inflammatory pattern of refractory asthma. For the first time, we showed that two potent markers of airway remodeling PDGF-BB and TIMP-2 correlate with the FeNO level in children with refractory asthma. Such correlations seem to be of great interest since airways remodeling has been found to be one of major factors deciding on the weak answer to antiasthma therapy. Tissue inhibitory of metalloproteinase 2 is an important mediator of extracellular matrix turnover, however its role in asthma is still not fully understood [14]. Platelet-derived growth factor-BB is a well-known airway smooth muscle (ASM) mitogen in vitro [15]. It has been shown recently that PDGF-BB overexpression resulted in airway hyperresponsiveness, decreased lung compliance, increased airway smooth muscle cell numbers and consequently changed lung mechanics in mice [16]. Interestingly, during periods of allergen exposure the PDGF-BB level has been elevated in lungs and was associated with changes in the airway structure and function [16].

Collectively, all above findings showed that a high FeNO level may reflects various unwelcome inflam- 

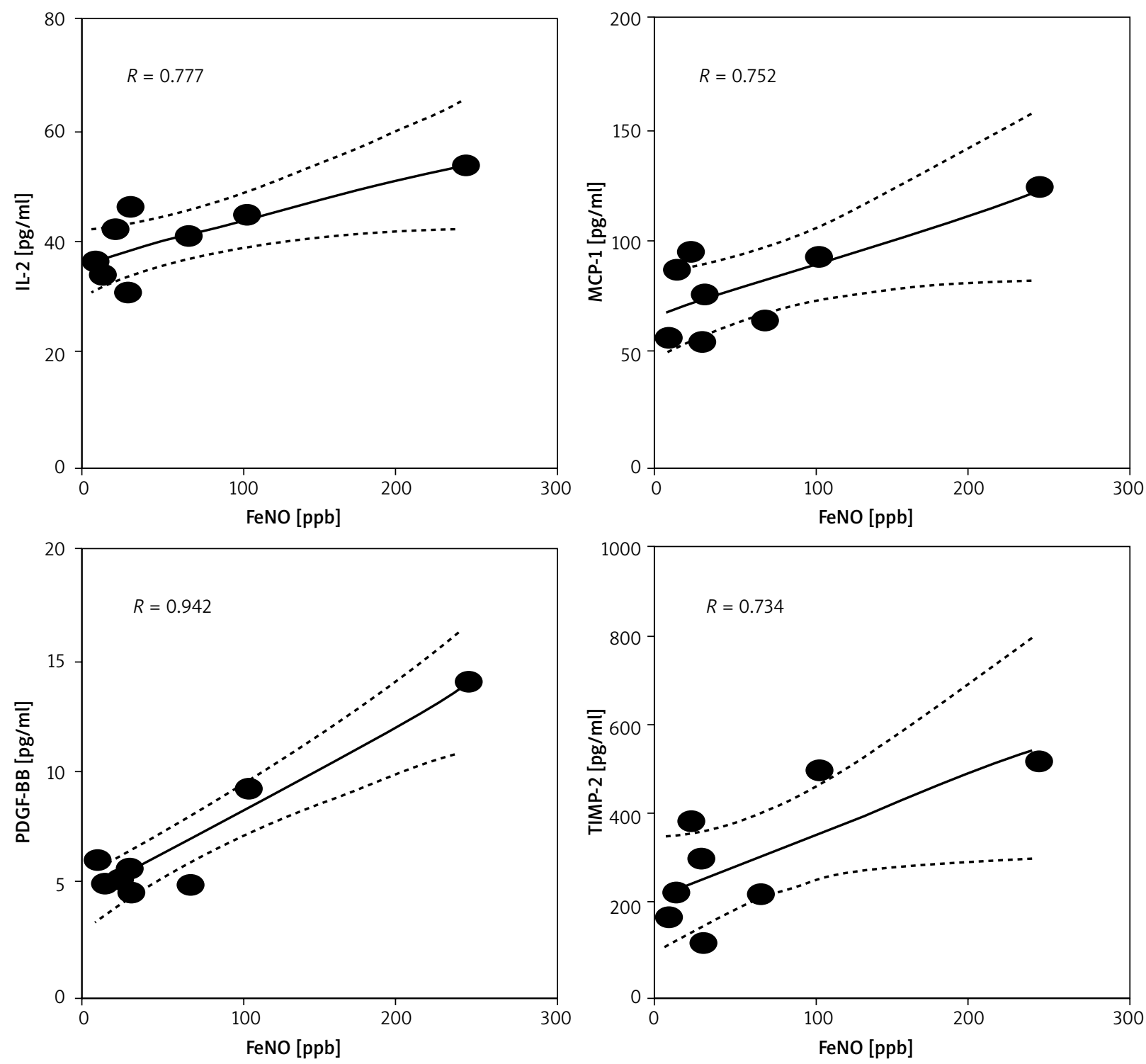

Figure 1. Correlations between cytokines (IL-2, MCP-1, PDGF-BB, TIMP-2) concentration in the airways and the fractional exhaled nitric oxide FeNO level

matory processes and it cannot be ignored in clinical practice.

When compared to previous studies in children with mild to moderate asthma, the concentration of TNF- $\alpha$ in our severe/refractory asthmatic children seems to be significantly higher $[11,17]$. However, IFN- $\gamma$, IL-1 $\alpha$, IL-2, IL-5, IL-6, IL-12p70 and IL-13 are lower than previously reported [11]. In contrast to a recently published study [18], we observed a significant correlation between $\mathrm{FEV}_{1}$ and IL-10, however all other cytokines were not correlated with FEV in our patients.

A similar cytokine profile in bronchoalveolar lavage (BAL) in children with severe asthma was characterized by Bossley et al.; there was no increase in BAL fluid of IL-4, IL-5, or IL-13 levels in patients with severe asthma compared with controls, and these cytokines were rarely detected in induced sputum [19]. Available data suggest that activation of the TNF- $\alpha$ axis is fundamental to the process leading to asthma and, particularly, to the development of the persistent airflow limitation and bronchial hyperreactivity in patients with refractory asthma [20]. Interestingly, it has been shown that eosinophilic inflammation of the airway is not linked to bronchial hyperresponsiveness and that anti-TNF- $\alpha$ did not reduce the total eosinophil cell counts in such patients. Also, exhaled NO, surrogate for eosinophilic airway inflammation was not affected by inhibition of TNF- $\alpha$ [20]. The above findings support the concept that bronchial hyperresponsiveness is not a direct consequence of nitric oxide levels or eosinophilia in severe/refractory 
Table 3. Partial correlations between cytokines

\begin{tabular}{|c|c|c|c|c|c|c|c|c|c|c|c|c|c|c|c|c|}
\hline & $\mathrm{N}-\gamma$ & IL-1a & IL-2 & IL-5 & IL-6 & IL-7 & IL-8 & IL-12p70 & IL-15 & IL-17 & MCP-1 & MIG & MIP1b & PDGFBB & TIMP2 & TNF- $\alpha$ \\
\hline IFN- $\gamma$ & & 0.45 & 0.74 & 0.76 & 0.45 & 0.79 & 0.33 & 0.33 & 0.55 & 0.29 & 0.45 & 0.74 & 0.69 & 0.05 & -0.05 & -0.67 \\
\hline IL-1a & 0.45 & & 0.24 & 0.31 & 0.19 & 0.48 & 0.14 & 0.14 & 0.38 & -0.31 & 0.24 & 0.29 & 0.26 & 0.14 & -0.21 & -0.74 \\
\hline IL-2 & 0.74 & 0.24 & & 0.17 & 0.90 & 0.45 & 0.83 & -0.07 & 0.76 & 0.02 & 0.71 & 0.29 & 0.31 & 0.19 & 0.29 & -0.14 \\
\hline IL-5 & 0.76 & 0.31 & 0.17 & & -0.17 & 0.71 & -0.31 & 0.50 & 0.07 & 0.52 & -0.02 & 0.83 & 0.64 & -0.14 & -0.36 & -0.79 \\
\hline IL-6 & 0.45 & 0.19 & 0.90 & -0.17 & & 0.31 & 0.98 & -0.17 & 0.81 & -0.21 & 0.86 & 0.10 & 0.12 & 0.33 & 0.52 & 0.14 \\
\hline IL-7 & 0.79 & 0.48 & 0.45 & 0.71 & 0.31 & & 0.19 & 0.52 & 0.69 & -0.05 & 0.60 & 0.71 & 0.67 & -0.12 & 0.02 & -0.50 \\
\hline IL-8 & 0.33 & 0.14 & 0.83 & -0.31 & 0.98 & 0.19 & & -0.24 & 0.74 & -0.31 & 0.83 & 0.02 & 0.05 & 0.36 & 0.57 & 0.24 \\
\hline IL-12p70 & 0.33 & 0.14 & -0.07 & 0.50 & -0.17 & 0.52 & -0.24 & & 0.17 & 0.36 & 0.21 & 0.33 & 0.88 & 0.36 & 0.38 & -0.24 \\
\hline IL-15 & 0.55 & 0.38 & 0.76 & 0.07 & 0.81 & 0.69 & 0.74 & 0.17 & & -0.40 & 0.90 & 0.17 & 0.33 & 0.05 & 0.38 & 0.00 \\
\hline IL-16 & 0.21 & -0.19 & -0.33 & 0.64 & -0.52 & 0.36 & -0.60 & 0.83 & -0.24 & 0.60 & -0.19 & 0.43 & 0.69 & 0.05 & 0.05 & -0.24 \\
\hline IL-17 & 0.29 & -0.31 & 0.02 & 0.52 & -0.21 & -0.05 & -0.31 & 0.36 & -0.40 & & -0.31 & 0.36 & 0.40 & 0.33 & 0.02 & -0.26 \\
\hline MCP-1 & 0.45 & 0.24 & 0.71 & -0.02 & 0.86 & 0.60 & 0.83 & 0.21 & 0.90 & -0.31 & & 0.26 & 0.38 & 0.33 & 0.67 & 0.14 \\
\hline MIG & 0.74 & 0.29 & 0.29 & 0.83 & 0.10 & 0.71 & 0.02 & 0.33 & 0.17 & 0.36 & 0.26 & & 0.57 & 0.05 & -0.10 & -0.64 \\
\hline MIP1b & 0.69 & 0.26 & 0.31 & 0.64 & 0.12 & 0.67 & 0.05 & 0.88 & 0.33 & 0.40 & 0.38 & 0.57 & & 0.38 & 0.36 & -0.43 \\
\hline PDGFBB & 0.05 & 0.14 & 0.19 & -0.14 & 0.33 & -0.12 & 0.36 & 0.36 & 0.05 & 0.33 & 0.33 & 0.05 & 0.38 & & 0.74 & 0.02 \\
\hline TIMP2 & -0.05 & -0.21 & 0.29 & -0.36 & 0.52 & 0.02 & 0.57 & 0.38 & 0.38 & 0.02 & 0.67 & -0.10 & 0.36 & 0.74 & & 0.52 \\
\hline$N F-\alpha$ & -0.67 & -0.74 & -0.14 & -0.79 & 0.14 & -0.50 & 0.24 & -0.24 & 0.00 & -0.26 & 0.14 & -0.64 & -0.43 & 0.02 & 0.52 & \\
\hline
\end{tabular}

All correlations between two different variables were controlled for the effect of all other variables. Data presented as a correlation coefficient; significant correlations are bolded.

asthma. Since we did not observe any correlation between TNF- $\alpha$ and NO concentrations in airways, our results seem to confirm the above hypothesis. It seems that up-regulation of TNF- $\alpha$ in airways of children with severe/refractory asthma reflects a distinct inflammatory process in contrast to the classic IgE-dependent answer to an allergen. Tumor necrosis factor- $\alpha$ may decide on severity of asthma as well as on the answer to corticosteroids. Therefore, we postulate to measure exhaled TNF- $\alpha$ in children with severe/refractory asthma followed by differential diagnosis of other possible reasons for TNF- $\alpha$ up-regulation. In children with refractory/severe asthma, measuring exhaled TNF- $\alpha$ seems to be helpful in approach to failure in asthma treatment. This is an observational study based on correlation's analysis in a relatively small sample size to draw general conclusions about potential correlations between FeNO and inflammatory markers. Therefore, our results must be confirmed in a larger population.

The detection rates were close to $100 \%$ for 13 cytokines and exceeded $50 \%$ for 20 cytokines. In addition, the inter-subject variability below $20 \%$ was observed for the following cytokines: IFN- $\gamma$, IL-2, IL-7, IL-15, IL-16, MIG and TNF- $\alpha$. Lower intra-subject variability was previously observed among healthy subjects and subjects with mild to moderate asthma and the authors concluded that in- tra-subject variability increased with the disease severity [7]. In our study, inter-subject variability was higher, what may indicate different inflammatory responses involved in pathophysiology of severe/refractory asthma in children. Although inter-subject variability in the present study seems to be wide, many correlations reached the level of significance, what improves the reliability of the findings.

The technique used in the present study during EBC analysis combines the advantages of the high detection sensitivity/specificity of ELISA and the high throughput of the arrays, what is necessary in assessment of inflammation in airways of children with severe/refractory asthma. The main results of this manuscript are that cytokines/ inflammatory markers are reproducibly measured in EBC, and that their expression correlates with exhaled nitric oxide levels. When treating asthma in children, the FeNO level should be closely monitored as a prevention strategy of the progression of the remodeling leading to refractory/severe asthma. Exhaled breath condensate may be a useful tool to phenotype or further characterize asthma via a non-invasive approach.

\section{Acknowledgments}

This study was funded by grant 503-2056-1 from the Medical University of Lodz, Poland. 


\section{Conflict of interest}

The authors declare no conflict of interest.

\section{References}

1. Ko FW, Leung TF, Hui DS. Are exhaled breath condensates useful in monitoring asthma? Curr Allergy Asthma Rep 2007; 7: 65-71.

2. Kostikas K, Koutsokera A, Papiris S, et al. Exhaled breath condensate in patients with asthma: implications for application in clinical practice. Clin Exp Allergy 2008; 38: 557-65.

3. Rutkowski K, Sowa P, Rutkowska-Talipska J, et al. Allergic diseases: the price of civilisational progress. Postep Derm Alergol 2014; 31: 77-83.

4. ATS Proceedings of the ATS workshop on refractory asthma: current understanding, recommendations, and unanswered questions, American Thoracic Society. Am J Respir Crit Care Med 2000; 162: 2341-51.

5. Szefler SJ, Mitchell H, Sorkness CA, et al. Management of asthma based on exhaled nitric oxide in addition to guideline-based treatment for inner-city adolescents and young adults: a randomised controlled trial. Lancet 2008; 372: 1065-72.

6. Global Strategy for Asthma Management and Prevention NIH Publication No 02- 3659. Updated 2011 document. (Accessed July 30, 2012, at http://www.ginasthma.org/guidelines-gina-report-global-strategy-for-asthma.html).

7. Recommendations for standardized procedures for the on-line and off-line measurement of exhaled lower respiratory nitric oxide and nasal nitric oxide in adults and children-1999, This official statement of the American Thoracic Society was adopted by the ATS Board of Directors, July 1999. Am J Respir Crit Care Med 1999; 160: 2104-17.

8. Rosias PP, Robroeks CM, Kester A. Biomarker reproducibility in exhaled breath condensate collected with different condensers. Eur Respir J 2008; 31: 934-42.

9. Inoue K, Takano H, Koike E, et al. Peroxiredoxin I is a negative regulator of Th2-dominant allergic asthma. Int Immunopharmacol 2009; 9: 1281-8.

10. Loppow D, Huland E, Heinzer $\mathrm{H}$, et al. Interleukin-2 inhalation therapy temporarily induces asthma-like airway inflammation. Eur J Med Res 2007; 12: 556-62.

11. Robroeks CM, Rijkers GT, Jöbsis Q, et al. Increased cytokines, chemokines and soluble adhesion molecules in exhaled breath condensate of asthmatic children. Clin Exp Allergy 2010; 40: 77-84.

12. Tonnel AB, Gosset P, Tillie-Leblond I. Characteristics of the Inflammatory response in bronchial lavage fluids from patients with status asthmaticus. Int Arch Allergy Immunol 2001; 124: 267-71.

13. Tillie-Leblond I, Hammad H, Desurmont S, et al. CC chemokines and interleukin-5 in bronchial lavage fluid from patients with status asthmaticus. Potential implication in eosinophil recruitment. Am J Respir Crit Care Med 2000; 162: 586-92.

14. Fu L, Sun G, Fiorentino M, et al. Characterization of Xenopus tissue inhibitor of metalloproteinases-2: a role in regulating matrix metalloproteinase activity during development. PLoS One 2012; 7: e36707.

15. Yahiaoui L, Villeneuve A, Valderrama-Carvajal A, et al. Endothelin-1 regulates proliferative responses, both alone and synergistically with PDGF, in rat tracheal smooth muscle cells. Cell Physiol Biochem 2006; 17: 37-46.

16. Hirota JA, Ask K, Farkas L, et al. In vivo role of platelet-derived growth factor-BB in airway smooth muscle proliferation in mouse lung. Am J Respir Cell Mol Biol 2011; 45: 566-72.
17. Robroeks CM, van de Kant KD, Jöbsis Q, et al. Exhaled nitric oxide and biomarkers in exhaled breath condensate indicate the presence, severity and control of childhood asthma. Clin Exp Allergy 2007; 37: 1303-11.

18. Boonpiyathad S, Pornsuriyasak P, Buranapraditkun S, Klaewsongkram J. Interleukin-2 levels in exhaled breath condensates, asthma severity, and asthma control in nonallergic asthma. Allergy Asthma Proc 2013; 34: e35-41.

19. Bossley CJ, Fleming L, Gupta A, et al. Pediatric severe asth$\mathrm{ma}$ is characterized by eosinophilia and remodeling without $\mathrm{T}(\mathrm{H}) 2$ cytokines. J Allergy Clin Immunol 2012; 129: 974-82.

20. Berry MA, Hargadon B, Shelley M, et al. Evidence of a role of tumor necrosis factor alfa in refractory asthma. N Engl J Med 2006; 354: 697-708. 